\title{
Impacts of COVID-19 pandemic on urban park visitation: a global analysis
}

\author{
Dehui (Christina) Geng ${ }^{1} \cdot$ John Innes ${ }^{1} \cdot$ Wanli Wu ${ }^{1}$ • \\ Guangyu Wang1
}

Received: 21 August 2020 / Accepted: 20 October 2020 / Published online: 12 November 2020

(C) The Author(s) 2020

\begin{abstract}
The COVID-19 pandemic has resulted in over 33 million confirmed cases and over 1 million deaths globally, as of 1 October 2020. During the lockdown and restrictions placed on public activities and gatherings, green spaces have become one of the only sources of resilience amidst the coronavirus pandemic, in part because of their positive effects on psychological, physical and social cohesion and spiritual wellness. This study analyzes the impacts of COVID-19 and government response policies to the pandemic on park visitation at global, regional and national levels and assesses the importance of parks during this global pandemic. The data we collected primarily from Google's Community Mobility Reports and the Oxford Coronavirus Government Response Tracker. The results for most countries included in the analysis show that park visitation has increased since February 16th, 2020 compared to visitor numbers prior to the COVID-19 pandemic. Restrictions on social gathering, movement, and the closure of workplace and indoor recreational places, are correlated with more visits to parks. Stay-at-home restrictions and government stringency index
\end{abstract}

Project funding: The research was supported by the APFNet National Park Research Project (2017SP2-UBC).

The online version is available at http://www.springerlink.com.

Corresponding editor: Yu Lei

Electronic supplementary material The online version of this article (https://doi.org/10.1007/s11676-020-01249-w) contains supplementary material, which is available to authorised users.

Guangyu Wang

Guangyu.wang@ubc.ca

1 Faculty of Forestry, University of British Columbia, 2424 Main Mall, Vancouver, BC V6T 1Z4, Canada are negatively associated with park visits at a global scale. Demand from residents for parks and outdoor green spaces has increased since the outbreak began, and highlights the important role and benefits provided by parks, especially urban and community parks, under the COVID-19 pandemic. We provide recommendations for park managers and other decision-makers in terms of park management and planning during health crises, as well as for park design and development. In particular, parks could be utilized during pandemics to increase the physical and mental health and social well-being of individuals.

Keywords COVID-19 · COVID-19 response policies . Parks visitation · Stepwise regression analysis · Urban parks

\section{Introduction}

The COVID-19 has been characterized as a pandemic by the World Health Organization due to the high numbers of confirmed cases and deaths, and has posed an unprecedented health crisis to human beings (Chan et al. 2020; Stier et al. 2020; WHO 2020). As of 1 October 2020, the pandemic has caused over 33 million confirmed cases and over 1 million deaths globally (Johns Hopkins University 2020). Restrictions on the use of public spaces, quarantine and social distancing are key measures implemented to tackle the COVID-19 pandemic and protect public health. Countries across the world have introduced policies such as stay-at home-lockdowns, restrictions on public events, social gatherings and public transport, the closure of schools and workplaces, and public COVID-19 information campaigns (Honey-Roses et al. 2020; Ritchie et al. 2020a). With the use of leisure facilities such as shopping malls, restaurants and 
recreational places, the cancellation of social activities, and the requirements of self-quarantine and social distancing, all being restricted, parks and green spaces have become increasingly popular and important for public health and social benefits (Twohig-Bennett and Jones 2018).

During the COVID-19 pandemic, quarantine and selfisolation, potential health issues and uncertainty, limited outdoor and social activities, social media exposure with negative news, and other pandemic-driven stressors such as financial problems and food insecurity, have all resulted in negative physiological and psychological effects for people. Symptoms include fatigue, tiredness, insomnia, posttraumatic stress symptoms, anxiety, loneliness, confusion, depression and anger. These have posed a threat to humans' mental and physical health, as well as social cohesion and resilience (Bo et al. 2020; Brooks et al. 2020; Monson et al. 2017; Gao et al. 2020; Wu et al. 2005; Xiang et al. 2020). During the COVID-19 pandemic, parks and green spaces are receiving renewed attention due to their significant and irreplaceable functions, such as providing places for healthy outdoor recreation (Rice and Pan 2020; Rung et al. 2011; Samuelsson et al. 2020). Urban parks and green spaces have been recognized as green infrastructure that provide and deliver environmental, social, psychological and health functions and ecological services for residents. They also provide people with multiple opportunities in terms of recreation and support people health, community cohesion and city sustainability (Chen et al. 2018; Chiesura 2004; Wolff et al. 2020). As well, under health crisis and global pandemic, parks and green spaces clearly benefit human mental and physical health, as well as social well-being (Holland et al. 2018; Thomsen et al. 2013).

Park visitation has changed during the COVID-19 pandemic, though the nature of this change has varied in different countries around the world. According to Google COVID-19 Community Mobility Reports (Ritchie et al. 2020b), park visitor numbers in most countries initially decreased before eventually increasing, and finally reaching levels equal to or even higher than a baseline taken as the mean value of daily park visitors between January 3rd and February 6th, 2020. Detailed analyses of the drivers contributing to changes in park visitor numbers during the COVID-19 pandemic are limited, especially at a global scale (Rice and Pan 2020). This paper therefore addressed the following research questions:

(1) What factors have affected the changes in park visitor numbers during the pandemic?

(2) What kind of relationship exists between daily park visitor numbers and the daily number of COVID-19 cases, and does this relationship vary under government policies, or according to economic, cultural and social factors?

(3) What are the roles of parks and green spaces during the COVID-19 pandemic? How can parks and green spaces systems best be managed to better serve the needs of urban residents during a pandemic?

\section{Materials and methods}

\section{Framework for COVID-19 impacts on park visitation analysis}

The overall framework of the research is shown in Fig. 1. This summarizes the data collection, analysis and methodology used here to analyze the impacts of COVID-19 on the change of park visitor numbers. The framework was structured and developed into two parts. The first part (in blue) included three categories of variables, including park visitor number changes, COVID-19 daily new cases, and government policies and restrictions. After the data collection, correlation analysis and stepwise regression analysis were used to analyze the impacts of COVID-19 and associated policies on park visitation at global, regional and national levels. The second part (in yellow) of this framework involved data collection based on selected countries' and regions' indices associated with social, economic, cultural and governance values and park visitation. This enabled the relationships between park visitation and various indices to be analyzed. A more detailed methodological description is provided below, as each step of the process is explained.

\section{The geographical scope of the study}

Countries were selected primarily because they had severe COVID-19 outbreaks. The selection was based on three severity indicators: cumulative number of COVID-19, infection rate and fatality rate. This resulted in the selection of 98 countries. The second step involved assessing data availability, and the last step was to screen and select countries and regions representing diverse economic, social and cultural dimensions. This process led to the selection of 48 countries and regions (in yellow) (Fig. 2).

\section{Data collection and variable selection}

\section{Park visitation data during the pandemic}

Park visitation data was obtained from the Google Community Mobility Report, which was first released on April 3rd, 2020, and provides a dataset that is regularly updated by Google and shows how the movements of people have changed every day since February 16th, 2020. The dependent variable for this study is the change in the number of park visitors in relation to a Pre-COVID baseline, which is extracted from this dataset. The dataset includes mobility information for individuals, and compares park visitation 


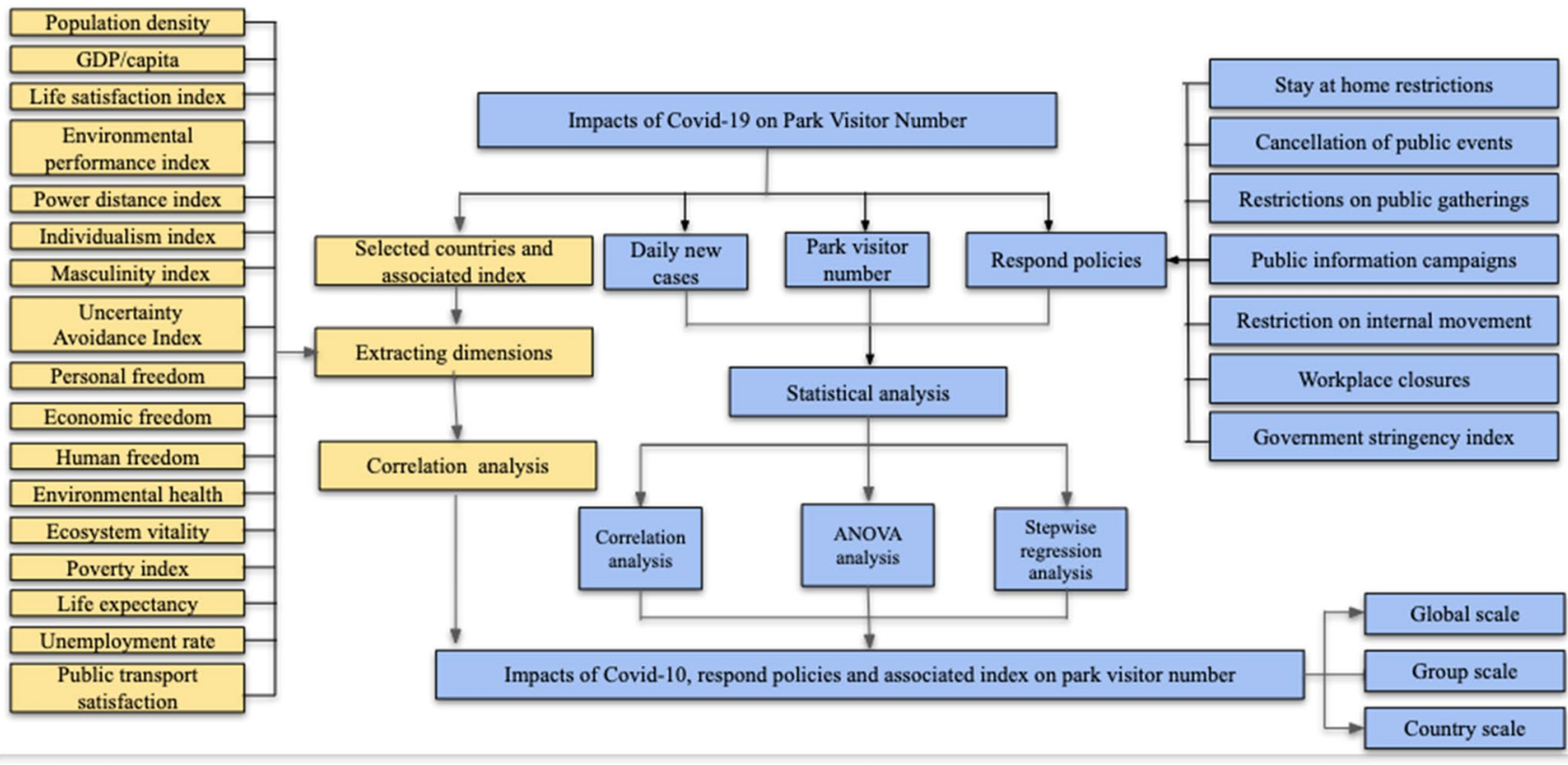

Fig. 1 Framework for COVID-19 impacts on park visitation analysis

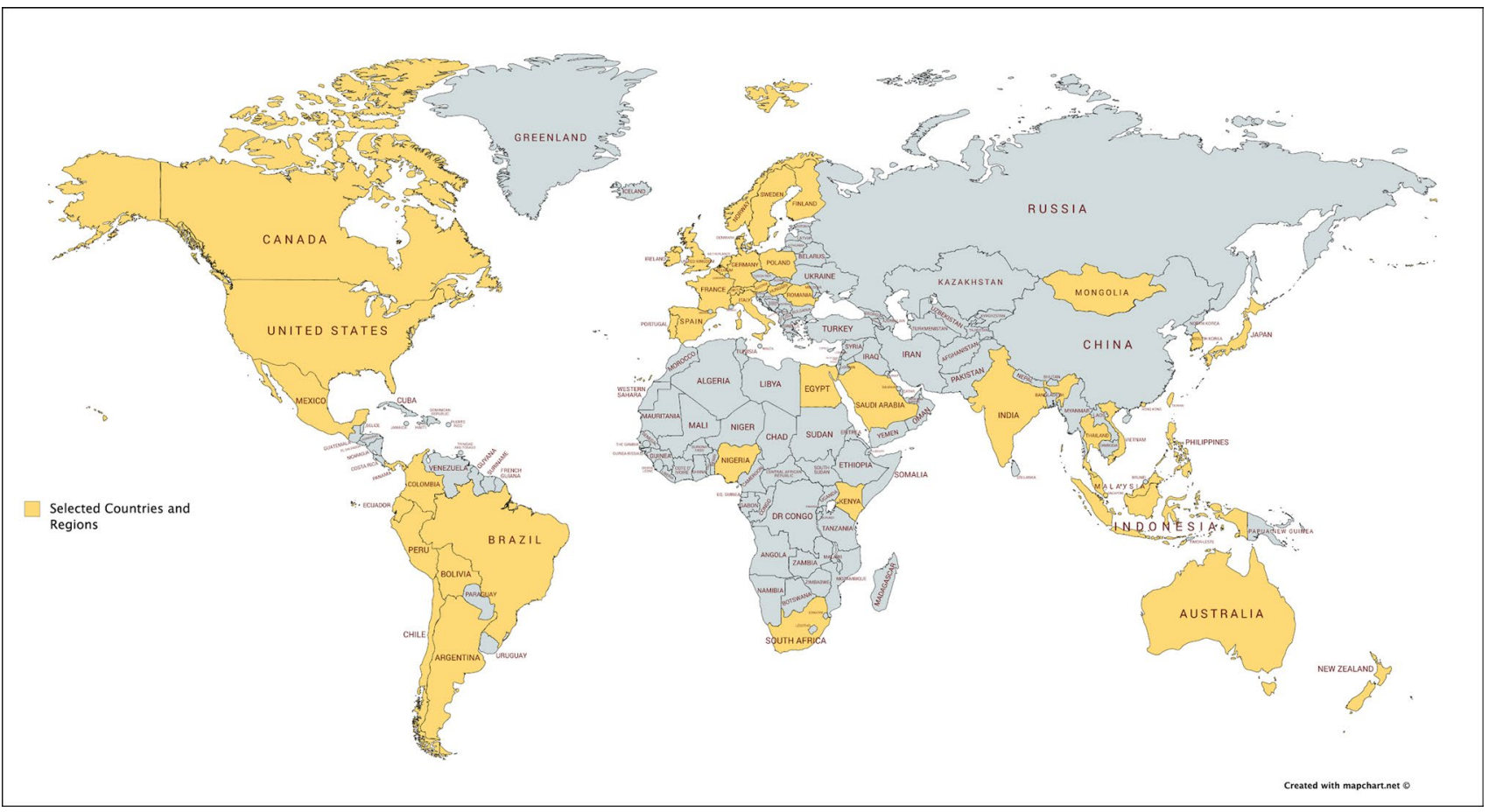

Fig. 2 The geographical scope of the study

and visitors' lengths of stays to the baseline visitor number that was collected in January before the COVID-19 pandemic widely started in 130 countries and regions around the world (Ritchie et al. 2020b). In this dataset, parks include outdoor places like local and community parks, national parks, public beaches, marinas, dog parks, plazas, and public gardens. In this study, park visitation data were statistically extracted from February 16th, 2020 to May 26th, 2020 that covers the first wave of COVID-19 
pandemic and right before the Black-Lives-Matter protests were occurred globally.

\section{The daily confirmed cases of COVID-19}

Data for the number of daily confirmed cases of COVID-19 were obtained from the World Health Organization (WHO) Health Emergency Dashboard. According to the dashboard, the data are refreshed every $15 \mathrm{~min}$, and are accurate at time of refreshing. Another dataset for daily confirmed cases of COVID-19 was used as an additional reference to correct and increase the accuracy of the data, which is published online by Our World in Data. These data were retrieved from the statistics and research work of many different people and organizations. To be consistent with the data for park visitation, the temporal scale of the daily confirmed cases of COVID-19 collection were collected from February 16th, 2020 to May 26th, 2020.

\section{Government policies at different stages}

Government policies and restrictions at different stages were collected and adapted from the Coronavirus Government Response Tracker (OxCGRT). OxCGRT is a data source published and updated by over 100 researchers at the Blavatnik School of Government at the University of Oxford. The tracker collects information on government responses to COVID-19 from every part of the world. OxCGRT collects and represents available information on 17 indicators of government responses and policies since January 2020 (Ritchie et al. 2020a). Seven of these indices were chosen as indicators: stay-at-home restrictions, cancellation of public events, restrictions on social gathering, public information campaigns, restrictions on internal movement, workplace closure, and the government stringency index. The categories and descriptions of each response are represented in Table S1. Government response data used in this study cover the period February 16th, 2020 to May 26th, 2020.

\section{Variables associated with social, economic, cultural and governance aspects}

Seventeen indices were collected to represent the economic, cultural, social and government dimensions of each country or region. They were: population density, GDP/capita, life satisfaction index, environmental performance index, power distance index, individualism index, masculinity index, uncertainty avoidance index, personal freedom index, economic freedom index, human freedom index, environmental health index, ecosystem vitality index, poverty index, life expectancy, unemployment rate, and public transport satisfaction. Specific information about each is given in Table S2.

\section{Statistical analysis}

Statistical analyses of the impacts of COVID-19 on park visitation were undertaken at global, regional and national scales, and included correlation analysis, ANOVA analysis and stepwise regression analysis. Stepwise regression analysis was a preferred tool as it involves no previous theoretical knowledge about the predicted impacts of COVID-19 and government responses on park visitation on a global scale. Stepwise regression analysis allows independent variables to be entered into the model based on statistical criteria, such as the $t$-value (Field 2009; Pallant 2010). Independent variables that have significant impacts on park visitation can thus be easier to identify.

Firstly, the impacts on the park visitation of COVID-19 and the subsequent government responses across 48 countries and regions were analyzed. After the global-level analysis, 48 countries and regions were classified into 6 groups based on the correlation between park visitor numbers, daily COVID-19 case increases and government responses. After the classification, stepwise regression analysis was conducted on each group, respectively. In the final step, 1-2 countries or regions were selected in each group as representative and were the subject of more detailed analyses of the drivers and impacts of selected independent variables on changes in park visitor numbers. Finally, a correlation analysis was conducted to investigate the relationships between the 17 indices and changes in park visits.

\section{Results}

\section{Global-scale analysis of the impacts of COVID-19 on park visitation}

Table 1 shows the correlations between the changes in park visitor numbers, COVID-19 daily case increases and the nine government responses for 48 countries. All ten independent variables were significantly correlated with changes in park visitor numbers at a $99 \%$ confidence interval. In the global-scale analysis, all variables were negatively correlated with changes in park visits. Among ten independent variables, stay at home restrictions were the most significant factor negatively correlated with changes in the number of park visits, followed by the restrictions on public transport and internal movement. The daily increase in the number of COVID-19 cases had the least significant effect on changes in park visitor numbers in the global-scale analysis.

Before applying the stepwise regression analysis, several assumptions were examined. First, the variables were tested for normality, using skewness and kurtosis values to determine whether they fitted a normal distribution with a statistical significance level of $95 \%$. After the significance 
Table 1 Correlation and significance tests between park visitor numbers, COVID-19 and government responses at a global scale

\begin{tabular}{|c|c|c|c|c|c|c|c|c|c|}
\hline & & $\begin{array}{l}\text { Daily case } \\
\text { increase }\end{array}$ & $\begin{array}{l}\text { Restrictions } \\
\text { on stay at } \\
\text { home }\end{array}$ & $\begin{array}{l}\text { Public event } \\
\text { cancellation }\end{array}$ & $\begin{array}{l}\text { Social } \\
\text { gathering } \\
\text { restriction }\end{array}$ & $\begin{array}{l}\text { Public } \\
\text { information } \\
\text { campaign }\end{array}$ & $\begin{array}{l}\text { Internal } \\
\text { movement } \\
\text { restrictions }\end{array}$ & $\begin{array}{l}\text { Workplace } \\
\text { closure }\end{array}$ & $\begin{array}{l}\text { Government } \\
\text { stringency } \\
\text { index }\end{array}$ \\
\hline \multirow{3}{*}{$\begin{array}{l}\text { Park } \\
\text { visitor } \\
\text { number }\end{array}$} & $\begin{array}{l}\text { Pearson cor- } \\
\text { relation }\end{array}$ & $-0.052^{* *}$ & $-0.511^{* *}$ & $-0.346^{* *}$ & $-0.341^{* *}$ & $-0.141^{* *}$ & $-0.395^{* *}$ & $-0.405^{* *}$ & $-0.461^{* *}$ \\
\hline & $\begin{array}{l}\text { Sig. } \\
\text { (2-tailed) }\end{array}$ & 0 & 0 & 0 & 0 & 0 & 0 & 0 & 0 \\
\hline & $\mathrm{N}$ & 4848 & 4848 & 4848 & 4848 & 4848 & 4848 & 4848 & 4848 \\
\hline
\end{tabular}

* indicates $P \leq 0.05$; ** indicates $P \leq 0.01$, bold font indicates statistical significance

test, the variance inflation factor (VIF) and tolerance values were calculated to ensure there were no multicollinearity problems. The VIF of all variables were more than 0.1 , and the tolerance values were less than 10 , indicating that the variables passed the multicollinearity test. The results of the stepwise regression analysis are shown in Tables 2 and 3.

Table 2 shows the variables entered or removed in each step of the stepwise regression model based on the $t$-value of each independent variable. All independent variables were selected in the model because each contributed significantly to the predictive ability of the model. Stay at home restrictions were the most important impact factor and were selected first selected by the model due to having the highest $t$-value, followed by daily increases in COVID-19 cases, government stringency index, social gathering restrictions, public information campaigns, public event cancellations, and workplace closures. The least important was the internal movement restrictions, which received the lowest $t$-value and thus was last selected by the model.

The stepwise regression model summary and coefficient analysis were analyzed as shown in Table 2 and Table S3. All eight independent variables had a significant impact on changes in park visitor numbers, with an $R$-value is equal to 0.535 . Among the eight variables, stay at home restrictions were selected first by the model and contributed significantly to a higher R-value compared to the other variables, explaining $26.1 \%$ of the variable (Table 4 ). The remaining factors potentially affecting changes in visits only contributed to explaining $2.5 \%$ of the variance.

A coefficient analysis was conducted to find out if the independent variables were related to changes in park visits (Appendix C). Seven independent variables were related to changes in park visitor numbers, including stay at home restrictions (std. coefficient $\beta=-0.341, p<0.001$ ), the daily increase COVID-19 cases (std. coefficient $\beta=0.025$, $p=0.065$ ), the government stringency index (std. coefficient $\beta=-0.645, p<0.001$ ), social gathering restrictions (std. coefficient $\beta=0.19, p<0.001$ ), public information campaigns (std. coefficient $\beta=0.13, p<0.001$ ), public event cancellations (std. coefficient $\beta=0.126, p<0.001$ ), workplace closures (std. coefficient $\beta=0.092, p=0.001$ ), and movement restrictions (std. coefficient $\beta=0.048, p=0.039$ ).

The standardized coefficient $\beta$ values for stay at home restrictions and government stringency index were negative, meaning that these two public response variables were significantly and negatively associated with park visitor numbers. However, the remaining independent variables, including daily COVID-19 increased cases, social gathering restrictions, public information campaigns, public event cancellations, workplace closures and movement restrictions received positive standardized coefficient $\beta$ values, indicating that they were positively associated with park

Table 2 Variables entered in the stepwise regression model for the global scale

\begin{tabular}{|c|c|c|c|c|c|c|c|c|c|c|}
\hline \multirow[t]{2}{*}{ Model } & \multirow[t]{2}{*}{ Variable entered } & \multirow[t]{2}{*}{$R$} & \multirow[t]{2}{*}{$R^{2}$} & \multirow[t]{2}{*}{ Adjusted $R^{2}$} & \multirow{2}{*}{$\begin{array}{l}\text { Std. Error of } \\
\text { the Estimate }\end{array}$} & \multirow[t]{2}{*}{ R Square Chang } & \multicolumn{4}{|c|}{ Change Statistics } \\
\hline & & & & & & & F Change & df1 & df 2 & Sig. F Change \\
\hline 1 & Stay at home restriction & 0.511 & 0.261 & 0.261 & 36.46459 & 0.261 & 1712.843 & 1 & 4846 & 0 \\
\hline 2 & Daily COVID-19 increase case & 0.515 & 0.266 & 0.265 & 36.35891 & 0.004 & 29.211 & 1 & 4845 & 0 \\
\hline 3 & Government stringency index & 0.518 & 0.269 & 0.268 & 36.282 & 0.003 & 21.564 & 1 & 4844 & 0 \\
\hline 4 & Social gathering restriction & 0.524 & 0.275 & 0.274 & 36.13209 & 0.006 & 41.277 & 1 & 4843 & 0 \\
\hline 5 & Public information campaign & 0.531 & 0.282 & 0.282 & 35.95051 & 0.007 & 50.047 & 1 & 4842 & 0 \\
\hline 6 & Public event cancelation & 0.534 & 0.285 & 0.284 & 35.89664 & 0.002 & 15.542 & 1 & 4841 & 0 \\
\hline 7 & Workplace closure & 0.535 & 0.286 & 0.285 & 35.866 & 0.001 & 9.276 & 1 & 4840 & 0.002 \\
\hline 8 & Internal Movement restrictions & 0.535 & 0.287 & 0.286 & 35.85393 & 0.001 & 4.259 & 1 & 4839 & 0.039 \\
\hline
\end{tabular}




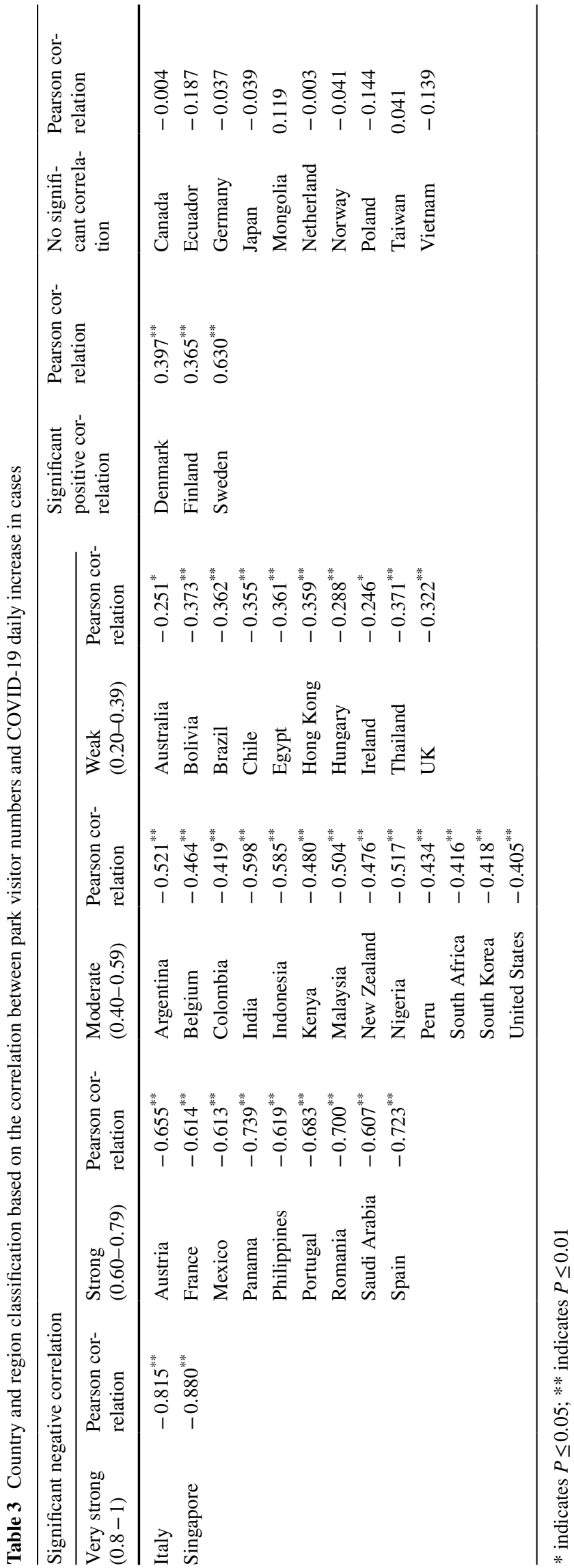

visits. Among these independent variables, the government stringency index received the highest absolute value for the standard coefficient, followed by the stay at home restriction, whereas the daily increase in COVID-19 cases received the lowest value. In the stepwise regression model, the higher the Beta values, the greater the importance of that variable in the model, indicating that the government stringency index is the most important independent variable in the model in the global-scale analysis.

\section{Regional scale analysis of the impacts of COVID-19 park visits}

Regional scale impacts of COVID-19 on park visits were analyzed to further understand and address the research questions at the regional level. First, 48 countries were grouped into six categories based on the correlation between changes in park visitor numbers and increases in daily COVID-19 cases. The correlation classification included significant negative correlations, significant positive correlations and no significant correlations. Countries that received significant negative correlations were grouped into a subclassification, including very strong (Pearson correlation between $0.80-1.00)$, strong $(0.60-0.79)$, moderate (0.40-0.59) and weak (0.20-0.39) significant negative correlation. The countries and regions contained in each group are listed in Table 3. After classifying 48 countries and regions into 6 groups, a stepwise regression analysis was performed on each group (Table S4).

The regional scale analysis revealed that the government stringency index was the most important variable with the highest $t$-value. It was the first selected in the stepwise regression model in most groups. The coefficient of government stringency index changed from negative to positive with the change of the correlation between park visitation change and daily increased cases of COVID-19 from a very strong negative correlation to a significant positive correlation. Among the eight COVID-19 related variables, social gathering restriction and public information campaign always had significant positive associations with changes in park visits, indicating that the stricter the social gathering restriction and the more widespread the public COVID19 information campaign, the more people went to parks and the longer they stayed. Among the strong and moderate negative correlation groups, all COVID-19 responses policies received a positive coefficient, which indicates that these variables had positive associations with increased park visitation. 
Table 4 Impacts of Covid-19 on park visits in selected countries and regions

\begin{tabular}{|c|c|c|c|c|c|c|c|}
\hline Countries & Variable & Model 1 & Model 2 & Model 3 & Model 4 & Model 5 & Model 6 \\
\hline \multirow[t]{6}{*}{ Italy } & Daily increase cases & $-0.815^{* *}$ & $-0.483 * *$ & $-0.375^{* *}$ & $-0.465 * *$ & $-0.370 * *$ & $-0.277 * *$ \\
\hline & Government stringency index & & $-0.469 * *$ & $-0.864 * *$ & $-1.010 * *$ & $-1.254 * *$ & $-1.470 * *$ \\
\hline & Internal movement restriction & & & $0.426^{* *}$ & $0.374 * *$ & $0.382 * *$ & $0.221 * *$ \\
\hline & stay at home restriction & & & & $0.289 * *$ & $0.287 * *$ & 0.149 \\
\hline & Public event cancellation & & & & & & $0.322 * *$ \\
\hline & Workplace closure & & & & & & $0.373 * *$ \\
\hline \multirow[t]{2}{*}{ Spain } & Daily increase cases & $-0.828 * *$ & $-0.622 * *$ & & & & \\
\hline & Government stringency index & & $-0.398 * *$ & & & & \\
\hline \multirow[t]{2}{*}{ South Korea } & Workplace closure & $0.493 * *$ & $0.384 * *$ & & & & \\
\hline & Daily increase cases & & $-0.251 * *$ & & & & \\
\hline \multirow[t]{3}{*}{ United Kingdom } & Internal movement restriction & $-0.387 * *$ & $-1.618 * *$ & -0.063 & & & \\
\hline & Social gathering restriction & & $1.331 * *$ & $1.483 * *$ & $1.484 * *$ & & \\
\hline & Stay at home restriction & & & $-1.706^{* *}$ & $-1.770 * *$ & & \\
\hline Denmark & Workplace closure & $0.611 * *$ & & & & & \\
\hline Sweden & Daily increase cases & $0.630 * *$ & & & & & \\
\hline Japan & Stay at home restriction & $-0.204 * *$ & & & & & \\
\hline
\end{tabular}

* indicates $P \leq 0.05 ;$ ** indicates $P \leq 0.01$

\section{National and sub-national analyses on COVID-19 impacts on park visits}

Further analyses were undertaken for selected countries that represent each group. Seven countries were selected, including Italy, Spain, South Korea, United Kingdom, Denmark, Canada and Japan, representing a very strong significant negative correlation, strong significant negative correlation, moderate significant negative correlation, weak significant negative correlation, significant positive correlation and no significant correlation between park visitation change and daily COVID-19 cases, respectively. Sweden was also selected for country-specific analysis due to the unique responses adopted by the government in response to COVID-19. Impacts of COVID-19 on park visitation over time are shown in Fig. 3, and the results of each country's stepwise regression analysis are shown in Table 4.

As of May 26 2020, the number of park visits had increased in all the selected countries, although to different degrees. The increase in park visitors in Italy, Spain, South Korea, Sweden and Japan was between 0-50\% compared to the baseline, whereas the increase in park visits in the United Kingdom, Denmark and Canada was over $100 \%$. Italy and Spain showed a similar trend in park visitor numbers, first decreasing significantly with a more than an $80 \%$ reduction during March and April 2020. After the outbreak was controlled, park visitation started to increase in May 2020, and finally ended slightly above the baseline. For South Korea, park visits first decreased during the rapid outbreak in February and the beginning of March, and then increased until reaching $150 \%$ of the baseline visitor numbers, and then eventually declining and stabilizing at 50\% more than the baseline. Park visits in the United Kingdom first decreased, at the same time as new confirmed cases were increasing, and then increased rapidly after April, finally reaching $150 \%$ more than the baseline. For Denmark, park visits increased continuously during the pandemic, and visitor numbers have increased by up to $350 \%$. Compared to Denmark, park visits in Sweden and Japan did not significantly change, whereas, in Canada, park visitor numbers increased by $80 \%$ compared to the baseline visitor numbers.

The impact factors of COVID-19 and response policies varied significantly amongst different countries. For countries with severe COVID-19 pandemics such as Italy and Spain, the COVID-19 daily case increase was the first variable selected in the stepwise regression model with the highest t-value, explaining $66.3 \%$ and $66.1 \%$ of the variance, respectively. In these countries, the daily increase in cases had a significant negative impact on the change in park visits. For countries with relatively low COVID-19 cases and deaths, such as South Korea and Denmark, most government responses were unassociated with changes in park visits. It is also worth noting that workplace closure became the most significant variable that positively affected park visitor numbers, which was first selected by the model and explained $24.3 \%$ and $37.3 \%$ of the variance.

Among the selected 10 countries, the daily increase in cases, stay at home restrictions and the government stringency index usually received negative standardized coefficients, indicating that these variables negatively affected 
park visits. Other responses, such as workplace closures, social gathering restrictions, public event cancellations, and internal movement restrictions tended to affect park visitation positively.

\section{Correlation analysis between the 17 indices and park visitation}

Correlation analyses was conducted for each country using 17 indices representing economic, social and cultural dimensions. All indexes were significantly correlated with park visitation changes (Table 5). Variables that had positive impacts on park visitation included GDP/capita, life satisfaction index, environmental performance index, individualism index, personal freedom index, economic freedom index, human freedom index, environmental health index, ecosystem vitality index, life expectancy, and satisfaction with transportation. The human freedom index received the highest (positive) Pearson correlation, followed by personal freedom index, life satisfaction level, environmental performance index and GDP/capita. Negatively correlated variables included human density, power distance index, masculinity index, uncertainty avoidance index, poverty index and unemployment rate, with the power distance index having the greatest number of the highest negative value.

\section{Discussion}

\section{Impacts of COVID-19 and associated government responses on park visitation}

\section{Global-scale analysis}

Many governments implemented responses to COVID-19 rapidly. Near real-time information (such as the number of new cases each day) has been accompanied by dramatic changes in societal behavior (Hockings et al. 2020). At a global level, parks in most selected countries and regions have received more visitors since the COVID-19 pandemic began. The results are consistent with the findings of three regional-scale research in the United States and Germany, indicating that urban parks have received much more frequent visits during the COVID-19 pandemic (Derks et al. 2020; Fisher and Grima 2020; Rice and Pan 2020). Most government responses, including workplace closures, restrictions on social gatherings and internal movements, and public event cancellations were correlated with an increase in park visitor numbers, whereas at a global scale, the government stringency index and stay at home restrictions were correlated with reductions in park visits.

There are several possible reasons for these results, including the psychological impacts of government responses to COVID-19 and the increasing role of parks during a global pandemic. Responses such as the cancellation of public events and the restriction of social event significantly reduced people's daily social activities. Many people went further than the governments required, altering their behavior to reduce or avoid the perceived risk, and undertaking fewer daily activities (Ferguson 2007). Previous studies have indicated that confinement and reduced social and physical contact with others during major health crises tend to cause boredom, frustration, depression and a sense of isolation from friends and family, which further distress people psychologically and physiologically (Blendon et al. 2004; Braunack-Mayer et al. 2013; Brooks et al. 2020; Cava et al. 2005; Desclaux et al. 2017; DiGiovanni et al. 2004). Because of this psychological stress and reduced social contact with others, combined with increasing concerns about mental health, people may tend to use nearby parks and green spaces to seek out connections with nature and to reduce the negative impacts caused by self-quarantine. The second possible reason for the increasing park visitation may be related to the workplace closure policy. Working at home reduces commute time, so many people have much more flexible time to spend during the quarantine. Also, work at home policies significantly change peoples' daily routine. Based on previous research on the psychological impact of the SARS quarantine experience, a loss of routine can exacerbate peoples' stress and frustration and increase peoples' demand to go outdoors (Hawryluck et al. 2004; Reynolds et al. 2008; Robertson et al. 2004). If of other public places such as shopping malls and restaurants are also closed, parks become one of the only places people can go for outdoor activities (Fisher and Grima 2020), provided that they also are not closed or restricted.

\section{Regional analysis}

At this scale, the government stringency index was the most important variable and was the first selected by the model in most groups due to its high $t$-value. This is consistent with previous findings. Human behavior during a health crisis, such as social distancing or self-quarantine, is highly dependent on the stringency of the government response (Hussain 2020). Caley et al. (2008) found that cities and states that had a high stringency index during the Spanish Flu epidemic had a 30\% to 50\% lower rate of infected cases and fatality rates, respectively, compared to cities that had softer government responses.

At a regional scale, COVID-19 and the associated government responses had varied impacts on park visitation. Although the government stringency index was the first selected in the stepwise regression model in most regions, each region had different coefficients. The value of the coefficients of government stringency index changed from 
Italy

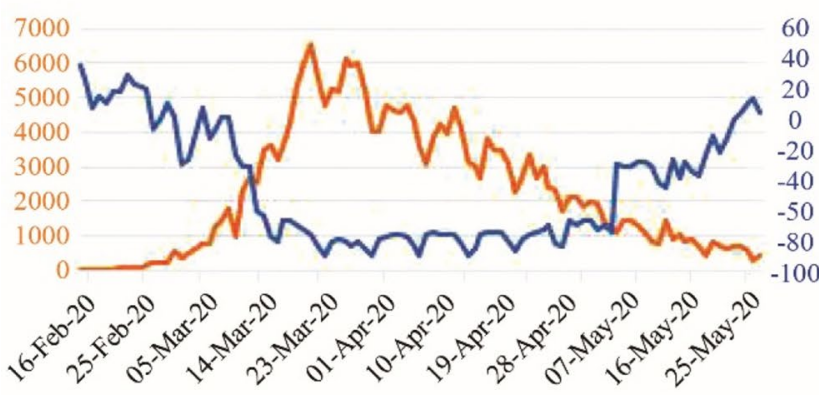

— New COVID-19 Cases — Park Visitor Number Change
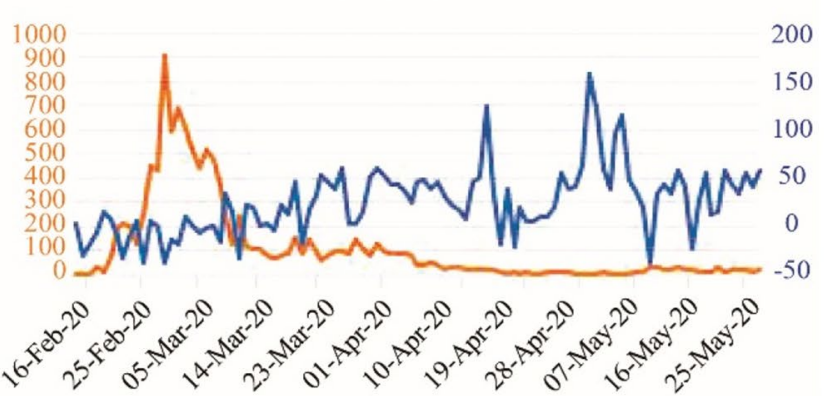

— New COVID-19 Cases _ Park Visitor Number Change

Denmark

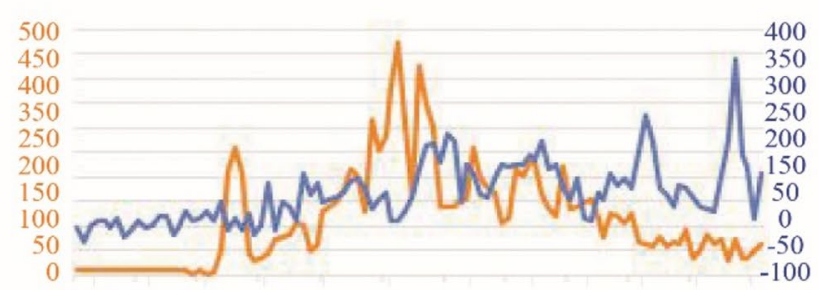

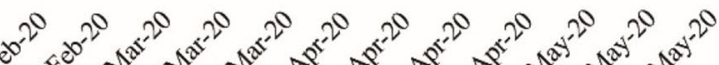

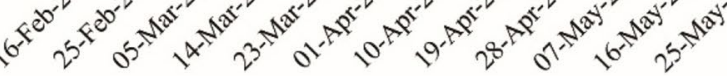

— New COVID-19 Cases — Park Visitor Number Change

Canada

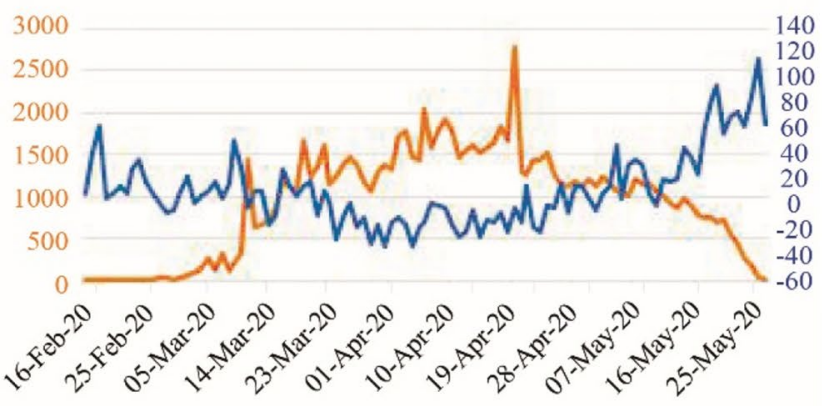

— New COVID-19 Cases — Park Visitor Number Change

Fig. 3 New COVID-19 cases and park visits in selected countries

Spain

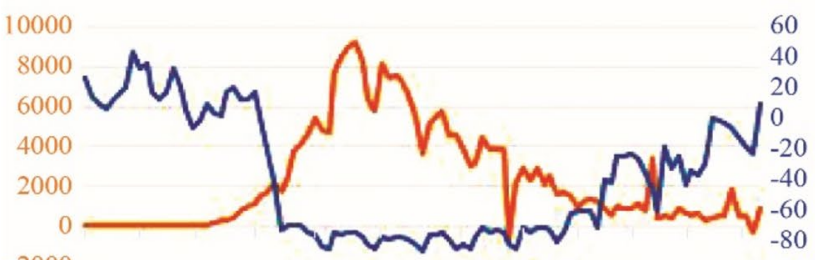

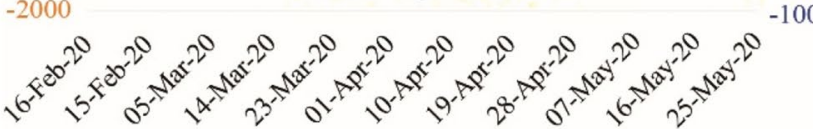

— New COVID-19 Cases — Park Visitor Number Change

United Kingdom

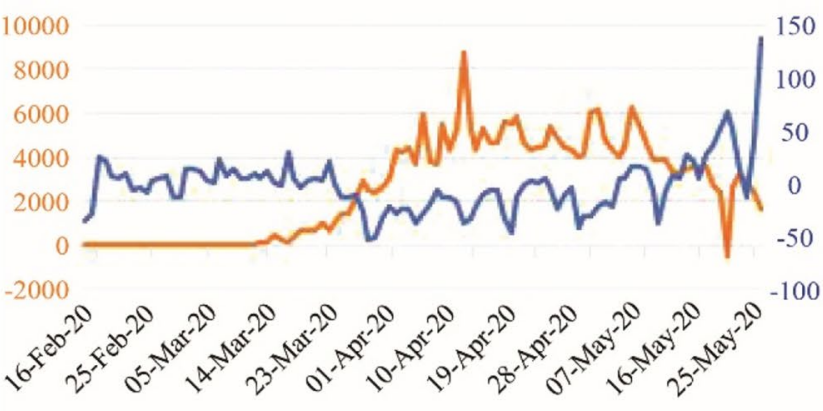

— New COVID-19 Cases _ Park Visitor Number Change

Sweden

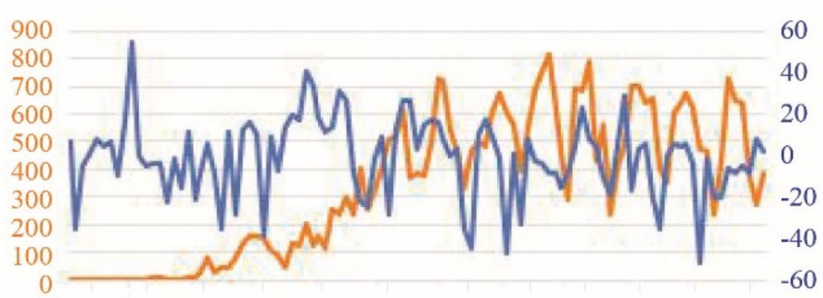

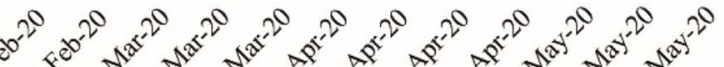

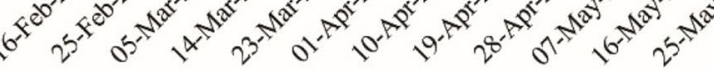

— New COVID-19 Cases _ Park Visitor Number Change

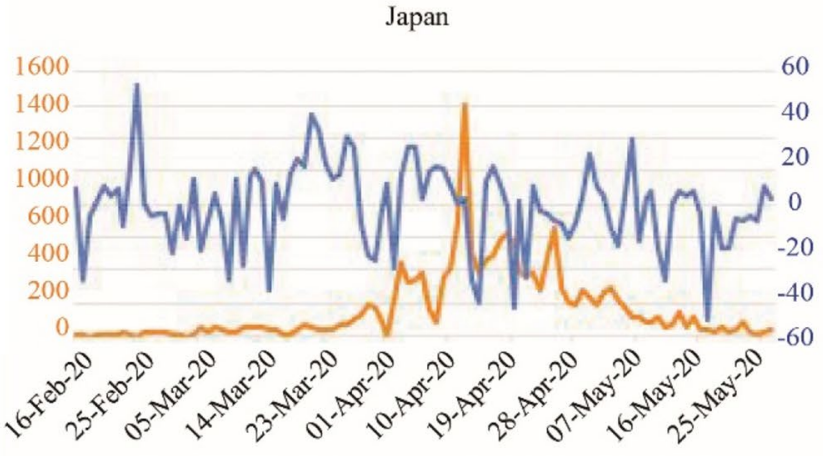

— New COVID-19 Cases — Park Visitor Number Change 
Table 5 Correlation between park visitation change and the 17 indices of economic, social and cultural factors

\begin{tabular}{lcl}
\hline Variable & Pearson correlation & $\begin{array}{l}\text { Sig. } \\
(2 \text {-tailed })\end{array}$ \\
\hline Human density & $\mathbf{- 0 . 0 3 5}^{*}$ & 0 \\
GDP/capita & $\mathbf{- 0 . 3 4 9 *}^{* *}$ & 0 \\
Life satisfaction index & $\mathbf{- 0 . 3 6 4}^{* *}$ & 0 \\
Environmental performance index & $\mathbf{- 0 . 3 5 9 ^ { * * }}$ & 0 \\
Power distance index & $\mathbf{- 0 . 4 3 0}^{* *}$ & 0 \\
Individualism index & $\mathbf{0 . 3 3 8}^{* *}$ & 0 \\
Masculinity index & $\mathbf{- 0 . 2 4 7}^{* *}$ & 0 \\
Uncertainty avoidance index & $\mathbf{- 0 . 2 0 6}^{* *}$ & 0 \\
Personal free index & $\mathbf{0 . 3 6 9}^{* *}$ & 0 \\
Economic free index & $\mathbf{0 . 2 9 5}^{* *}$ & 0 \\
Human free index & $\mathbf{0 . 3 7 7}^{* *}$ & 0 \\
Environmental health index & $\mathbf{0 . 3 1 0}^{* *}$ & 0 \\
Ecosystem vitality index & $\mathbf{0 . 3 1 8}^{* *}$ & 0 \\
Poverty index & $\mathbf{0 . 1 6 6}^{* *}$ & 0 \\
Life expectancy & $\mathbf{0 . 2 4 9}^{* *}$ & 0 \\
Unemployment rate & $\mathbf{0 . 1 0 1}^{* *}$ & 0 \\
Satisfaction with transportation & $\mathbf{0 . 0 6 8}^{* *}$ & 0 \\
\hline
\end{tabular}

* indicates $P \leq 0.05$; ** indicates $P \leq 0.01$, bold font indicates statistical significance

negative to positive with the change of the correlation between park visitation change and daily increased cases of COVID-19 from a very strong negative correlation to a significant positive correlation. This can be explained by the severity of the pandemic severity and the strictness of the government response in each region. For example, for countries that had severe cases of COVID-19 and strict government responses, the government stringency index tended to receive negative coefficient values, involving limiting the ability of people to visit parks. In countries such as Denmark and Finland, where the governments did not have strict response policies, especially at the beginning of the outbreak, and which experienced less severe cases of COVID-19, there were more positive coefficients of government stringency index and increased park visitation.

Among the selected variables, the existence of social gathering restrictions and public information campaigns always had significant positive impacts on park visitor numbers. The stricter the social gathering restriction was and the more widespread the public COVID-19 information campaign, the more people went to parks and the longer they stayed. Intensive COVID-19 information campaigns combined with the severity of the outbreak may have persuaded people to follow the rules, which they can often do when visiting a park.
National analyses

Park visitation in individual countries increased compared to park visitor numbers before the COVID-19 pandemic began. However, park visitation trends and levels differed between countries. The increase in park visitors in Italy, Spain, South Korea, Sweden and Japan was between 0-50\% compared to the baseline, whereas the increase of park visitation in the United Kingdom, Denmark and Canada was over $100 \%$. The differences reflect different response strategies. In countries such as Italy that experienced a severe COVID-19 outbreak and imposed very restrictive responses, park visitor numbers initially decreased significantly. Once the outbreak was controlled and the government lightened some restrictions, park visitation started to increase to levels slightly above baseline. For countries with fewer COVID-19 cases and less restrictive responses, park visitation increased continuously by over $100 \%$ compared to baseline. For example, in Canada and Denmark, the governments have "recommended stay at home" as the response policy since the start of the COVID-19 outbreak began, and more people accessed parks. It is worth noting that federal parks in Canada were actually closed to visitors, as were provincial parks in some provinces. Regional and municipal parks remained opened. Metro Vancouver (British Columbia, Canada) reported that $60 \%$ of its parks received higher visitation and utilization after the implementation of social distancing rules (Godfrey 2020).

In countries with severe COVID-19 outbreaks, the daily increase in cases was the most important variable that was negatively associated with park visitation. For countries with less severe outbreaks, neither the daily increase in cases nor government responses were associated with park visitor numbers. Workplace closures and social gathering restrictions were associated with increased visits, perhaps because people may use the time saved from their daily commute to go to parks and avoid the sense of isolation caused by reduced social contact.

In Sweden, the only variable associated with changes in visitor numbers was the daily increase in cases. This may be because Sweden sought to use herd immunity to control the disease, allowing a proportion of the population to get infected (Habib 2020; Randolph and Barreiro 2020). Bars, restaurants, and other public spaces remained open with much fewer restrictions, which may explain why only the daily increase in cases was associated with changes in visits. It may also explain why park visitation in Sweden did not significantly change during the pandemic. 


\section{The benefits of parks and green spaces under COVID-19 Pandemic}

\section{Benefits of parks on mental health and stress reduction}

Parks and green spaces are widely recognized as providing important public benefits, especially during health crises (National Recreation and Parks Association 2020). The spread of the disease and the implementation of government responses have resulted in some long-ignored functions of parks finally being recognized by the public (Hockings et al. 2020). Our results indicate that demand for park access increased during the pandemic. Other studies have also confirmed that during the COVID-19 pandemic, people re-evaluated the value of parks and green spaces, raising the importance of parks, especially urban parks and community parks which mostly have remained open (Fisher and Grima 2020; Freeman and Eykelbosh 2020; Nicola et al. 2020). Fisher and Grima (2020) investigated the use and value of urban and peri-urban natural areas to local communities under COVID-19 pandemic by using online survey, and $81 \%$ of respondents to a survey mentioned that the value of urban, peri-urban forests and other natural areas to them had increased or significantly increased since the pandemic began and social and work restrictions were implemented.

The COVID-19 pandemic has resulted in severe psychological burdens for many individuals around the world (Bavel et al. 2020). The impact of the pandemic, as well as self-quarantine and other response policies, on mental health is expected to be significant (Brooks et al. 2020; Freeman and Eykelbosh 2020). Drivers of negative impacts on people's mental health include the duration of quarantine, fears of infection, frustration and boredom, and inadequate information (Brooks et al. 2020). Longer durations of self-quarantine can lead to poorer mental health, post-traumatic stress symptoms and other negative psychological impacts (Bavel et al. 2020; de Bell et al. 2020; Brooks et al. 2020; Hossain et al. 2020; Reynolds et al. 2008; Wilken et al. 2017). More specifically, based on the research done by Hawryluck et al. (2004), people with more than 10 days quarantine have shown significantly higher stress symptoms compared with those quarantined for less than 10 days. Stress associated with quarantine is compounded by fears of infection for individuals and family, loss of usual routine, restrictions on social and physical contact, and lack of clear guidelines or rationale for COVID-19 information campaigns (Brooks et al. 2020; Braunack-Mayer et al. 2013). Parks and green spaces have played a role in mitigating the psychological burdens associated with COVID-19 (Freeman and Eykelbosh 2020).

Parks can reduce stress and offer various psychological and emotional benefits during a major health crisis
(Annerstedt et al. 2012; Hockings et al. 2020; Nicola et al. 2020; Seaman et al. 2010). They provide qualities like serenity, space, wildness, culture and a lush environment, which can all reduce the risk of poor mental health (Annerstedt et al. 2012). Many studies have confirmed that spending time in natural areas such as parks and green spaces can help people avoid a sense of isolation, reduce mental stress, improve sleep quality and thus reduce of the risk of depression and anxiety, and improve individuals' resilience and manageability of life tasks (Bratman et al. 2019; Cox et al. 2017; Fong et al. 2018; Hammen 2005; Rasmussen and Laumann 2013; Roe and Aspinall, 2011).

\section{Benefits of parks on physical health}

Government restrictions have curtailed many daily activities but parks have compensated by providing space for physical activity spaces and fresh air. Some people have realized that a rapid and well-coordinated immune system response combined with good physical health represents the first line of defense against infection (Catanzaro et al. 2020).

The physical benefits associated with the use of parks and other natural areas have been widely recognized (Fisher and Grima 2020; Seaman et al. 2010). The Center for Disease Control and Prevention in USA has shown that park visits can improve individual and community health, resulting in a 25\% increase in the perceived physical health of residents who exercise in parks at least three times per week (National Recreation and Parks Association 2020). The physical health benefits of access to urban parks is known improve cardiovascular health and pulmonary function (Lee and Lee 2014; Tamosiunas et al. 2014). Spending time in parks and other natural areas can activate Natural Killer (NK) cells in humans. NK cells are important in the human immune system as they induce virus-infected targeted cell death ( $\mathrm{Li}$ et al. 2007; Tsao et al. 2018; Vivier et al. 2008).

\section{Park benefits for reducing the risk of disease transmission and increasing social cohesion}

Access to parks could reduce the risk of COVID-19 transmission and increase community and social cohesion. If parks are closed or access is otherwise limited, people may move to less desirable public spaces, such as sidewalks and pavements. However, these public spaces are not designed to encourage and maintain physical distancing (Barkhorn 2020). Parks allow people to spread out, reducing crowding in less desirable areas (Freeman and Eykelbosh 2020; Public Health England 2014).

Parks, particularly community parks, may improve social cohesion at a community level and help build a sense of integration and inclusion amongst residents in their communities. Increased social and community cohesion and 
feelings of integration and belonging can reduce the risk of antisocial behavior especially during public health crises (Seaman et al. 2010).

\section{Recommendations and future park planning and development}

\section{Utilization of parks during the COVID-19 pandemic}

We suggest that the use of community parks and urban parks should not be restricted during the COVID-19 outbreak. Parks provide important ecosystem services that mitigate some of the stress associated with COVID-19 and ensure the mental and physical health of individuals. The implementation of government responses to COVID-19 significantly restricts peoples' social and physical contact with others. Many parks provide an opportunity for people to be outside without violating social distancing restrictions (Eagles 2020), and in addition to provide benefits that help people cope with physical and mental challenges posed by the pandemic. It is also worth noting that urban residents in countries with high infection rates and confirmed cases should also be encouraged to go to nearby community parks and green spaces as long as they follow the protective guidelines and instructions such as maintaining physical distancing from each other. Take the United States as an example, the government conducted shelter-in-place orders since March 2020, which has significantly restricted residents' movements and human interaction (Gostin and Wiley 2020). Under the closure of workplaces, schools, shopping malls, restaurants and other public places, the access of parks and open green spaces in the United States also got restricted by the policies. However, studies have been confirmed that these restrictions on parks and green spaces could possibly cause people severe physical and mental health issues especially those living in urban areas (Sallis and Pratt 2020; Slater et al. 2020).

With development of the COVID-19 pandemic, people have gradually increased their awareness to protect themselves against COVID-19 by understanding and practicing social-distancing rules in this new normal. Combined with the overall global pandemics have been brought relatively under control with more understanding to manage confirmed cases and reduce potential spread, some government restrictive policies such as stay at home restrictions are gradually liberalized in the community, allowing people to access their nearby parks and greenspaces to gain larger spaces for some recreational activities with more self-protections. On the basis that nowadays people understand and strictly abide by the social-distancing rules under the loosening of stayat-home restrictions, parks and green spaces may be utilized as important natural services to personal well-being and the society. The ecological services and functions provided by parks and greenspaces allow people to access and conduct physical exercise, reduce the mental stress while maintaining physical distance under the COVID-19 pandemic.

Park visitation and associated economic, cultural and social index

We also analyzed the correlation between park visitation and selected economic, cultural and social indexes for each country and region. Access to parks was unequal, and was significantly correlated with economic development, environmental performance and cultural characteristics.

The economic development index includes GDP per capita, power distance index, economic freedom index, poverty index and unemployment rate. Results indicate that park visitation was greater in more developed economies. Poor economic performance could lead to less access to parks, and thus compound the more negative impacts of COVID-19. This is consistent with Larson et al. (2016), Laster Pirtle (2020) and Nesbitt et al. (2019), who found unequal access to urban green spaces in US cities, with access being negatively correlated with poverty rate. The correlation analysis indicated that all the environmental performance factors had significant positive associations with park visitation.

Population density was significantly negatively associated with park visitation. Research done in Berlin showed that congested city streets and crowded apartment blocks may have a higher risk of infection than being in open spaces such as parks and green spaces, and raise the risk of mental health issues (Saunders and Evans 2020). The provision of urban parks and community greenspaces in areas with high population density appears to be particularly important.

\section{Conclusion}

In this study, we analyzed the association between the COVID-19 pandemic and associated government responses and park visitation at global, regional and national scales. Park visitation increased compared with a baseline developed before the outbreak began. Public policies that restricted people's social and physical contacts were associated with increased park visitation. Our findings suggest that the demand for access to parks and outdoor green spaces increased during the pandemic.

The study has a number of limitations. According to Google Community Mobility Report, the park visitation change was calculated compared with the "baseline" for the corresponding day of the week. The baseline visitor number was determined by the median value of park visitors from 
January 3rd to February 6th, 2020, which is immediately before COVID-19 started to become widespread. However, the change could also be related to the seasonal change of the weather and climate. Therefore, future work is needed to eliminate the seasonal effects on park visitation change. Future research also could focus on (1) further exploring the post-COVID-19 park visitor numbers and people's opinions about parks, and (2) conducting a community-scale correlation and stepwise regression model, as well as an assessment of the equality of access to parks amongst local residents.

Acknowledgements We sincerely thank to Prof. Cecil Konijnendijk provided his insightful feedback to this manuscript.

Open Access This article is licensed under a Creative Commons Attribution 4.0 International License, which permits use, sharing, adaptation, distribution and reproduction in any medium or format, as long as you give appropriate credit to the original author(s) and the source, provide a link to the Creative Commons licence, and indicate if changes were made. The images or other third party material in this article are included in the article's Creative Commons licence, unless indicated otherwise in a credit line to the material. If material is not included in the article's Creative Commons licence and your intended use is not permitted by statutory regulation or exceeds the permitted use, you will need to obtain permission directly from the copyright holder. To view a copy of this licence, visit http://creativecommons.org/licenses/by/4.0/.

\section{References}

Annerstedt M, Östergren PO, Björk J, Grahn P, Skärbäck E, Währborg P (2012) Green qualities in the neighbourhood and mental health-results from a longitudinal cohort study in Southern Sweden. BMC Public Health 12(1):337

Barkhorn E (2020) Rules for using the sidewalk during the coronavirus. New York Times. Retrieved from https://www.nytim es.com/2020/04/05/opinion/coronavirus-walk-outside.html

Bavel JJ, Baicker K, Boggio PS, Capraro V, Cichocka A, Cikara M, Drury J (2020) Using social and behavioural science to support COVID-19 pandemic response. Nat Hum Behav 4(5):460-471. https://doi.org/10.1038/s41562-020-0884-z

Blendon RJ, Benson JM, DesRoches CM, Raleigh E, Taylor-Clark K (2004) The public's response to severe acute respiratory syndrome in Toronto and the United States. Clin Infect Dis 38(7):925-931

Bo HX, Li W, Yang Y, Wang Y, Zhang Q, Cheung T, Xiang YT (2020) Posttraumatic stress symptoms and attitude toward crisis mental health services among clinically stable patients with COVID-19 in China. Psychol Med. https://doi.org/10.1017/ S0033291720000999

Bratman GN, Anderson CB, Berman MG, Cochran B, De Vries S, Flanders J, Kahn PH (2019) Nature and mental health: An ecosystem service perspective. Sci Adv 5(7):eaax0903. https://doi. org/10.1126/sciadv.aax0903

Braunack-Mayer A, Tooher R, Collins JE, Street JM, Marshall H (2013) Understanding the school community's response to school closures during the H1N1 2009 influenza pandemic. BMC Public Health, 13(1): 344. https://www.biomedcentral. com/1471-2458/13/344

Brooks SK, Webster RK, Smith LE, Woodland L, Wessely S, Greenberg N, Rubin GJ (2020) The psychological impact of quarantine and how to reduce it: rapid review of the evidence. Rapid Rev 295:912-920

Caley P, Philp DJ, McCracken K (2008) Quantifying social distancing arising from pandemic influenza. J R Soc Interface 5(23):631-639

Catanzaro M, Fagiani F, Racchi M, Corsini E, Govoni S, Lanni C (2020) Immune response in COVID-19: addressing a pharmacological challenge by targeting pathways triggered by SARSCoV-2. Signal Transduct Target Therapy 5(1):1-10

Cava MA, Fay KE, Beanlands HJ, McCay EA, Wignall R (2005) The experience of quarantine for individuals affected by SARS in Toronto. Public Health Nurs 22(5):398-406

Chan JFW, Yuan S, Kok KH, To KKW, Chu H, Yang J, Tsoi HW (2020) A familial cluster of pneumonia associated with the 2019 novel coronavirus indicating person-to-person transmission: a study of a family cluster. The Lancet 395(10223):514-523

Chen Y, Liu X, Gao W, Wang RY, Li Y, Tu W (2018) Emerging social media data on measuring urban park use. Urban For Urban Green 31:130-141

Chiesura A (2004) The role of urban parks for the sustainable city. Landsc and Urban plan 68(1):129-138

Cox DT, Hudson HL, Shanahan DF, Fuller RA, Gaston KJ (2017) The rarity of direct experiences of nature in an urban population. Landsc Urban Plan 160:79-84

de Bell S, White M, Griffiths A, Darlow A, Taylor T, Wheeler B, Lovell R (2020) Spending time in the garden is positively associated with health and wellbeing: Results from a national survey in England. Landscape and Urban Planning. https://hdl.handl e.net/10871/120955

Derks J, Giessen L, Winkel G (2020) COVID-19-induced visitor boom reveals the importance of forests as critical infrastructure. Forest Policy Econ. https://doi.org/10.1016/j.forpol.2020.102253

Desclaux A, Badji D, Ndione AG, Sow K (2017) Accepted monitoring or endured quarantine? Ebola contacts' perceptions in Senegal. Soc Sci Med 178:38-45

DiGiovanni C, Conley J, Chiu D, Zaborski J (2004) Factors influencing compliance with quarantine in Toronto during the 2003 SARS outbreak. Biosecur Bioterror 2(4):265-272

Eagles P (2020) Personal Opinions on the Canadian Park Use Restrictions due to the COVID-19 Pandemic. TAPAS Special Topic Webinar: Protected Areas and COVID-19. https://www.researchga te.net/publication/341411889

Ferguson N (2007) Capturing human behaviour. Nature 446(7137):733-733. https://doi.org/10.1038/446733a

Field A (2009) Discovering statistics using SPSS. Sage. Retrieved from https://sro.sussex.ac.uk/id/eprint/14911/

Fisher B, Grima N (2020) The importance of urban natural areas and urban ecosystem services during the COVID-19 pandemic. SocArXiv. https://doi.org/10.31235/osf.io/sd3h6

Fong KC, Hart JE, James P (2018) A review of epidemiologic studies on greenness and health: updated literature through 2017. Curr Environ Health Rep 5(1):77-87

Freeman S, Eykelbosh A (2020) COVID-19 and outdoor safety: Considerations for use of outdoor recreational spaces. National Collaborating Centre for Environmental Health. Retrieved from https ://www.researchgate.net/publication/340721289_COVID-19_ and_outdoor_safety_Considerations_for_use_of_outdoor_recre ational_spaces_Prepared_by

Gao J, Zheng P, Jia Y, Chen H, Mao Y, Chen S, Dai J (2020) Mental health problems and social media exposure during COVID-19 outbreak. PLoS ONE 15(4):e0231924. https://doi.org/10.1371/ journal.pone.0231924

Godfrey D (2020) No COVID-19-related park closures. Burnaby Now. 2020 Mar 26. Retrieved from: https://www.burnabynow .com/news/no-covid-19-related-park-closures-expected-in-burna by-1.24107029. 
Gostin LO, Wiley LF (2020) Governmental public health powers during the COVID-19 pandemic: stay-at-home orders, business closures, and travel restrictions. JAMA 323(21):2137-2138

Habib H (2020) Has Sweden's controversial covid-19 strategy been successful? BMJ 2020(369):m2376. https://doi.org/10.1136/bmj. $\mathrm{m} 2376$

Hammen C (2005) Stress and depression. Annu Rev Clin Psychol $1: 293-319$

Hawryluck L, Gold WL, Robinson S, Pogorski S, Galea S, Styra R (2004) SARS control and psychological effects of quarantine, Toronto. Can Emerg Infect Dis 10(7):1206-1212

Hockings M, Dudley N, Elliott W, Ferreira MN, Mackinnon K, Pasha MKS, Chassot O (2020) Editorial essay: Covid-19 and protected and conserved areas. Parks 26(1):7-24

Holland WH, Powell RB, Thomsen JM, Monz CA (2018) A systematic review of the psychological, social, and educational outcomes associated with participation in wildland recreational activities. J Outdoor Recreat Educ Leadersh. 10(3):197-225

Honey-Roses J, Anguelovski I, Bohigas J, Chireh V, Daher C, Konijnendijk C, Oscilowicz E (2020) The impact of COVID-19 on public space: a review of the emerging questions. https://doi. org/10.31219/osf.io/rf7xa

Hossain MM, Sultana A, Purohit N (2020) Mental health outcomes of quarantine and isolation for infection prevention: A systematic umbrella review of the global evidence. Epidemiol Health 42:e2020038. https://doi.org/10.4178/epih.e2020038 (Epub 2020 Jun 2 PMID: 32512661)

Hussain A (2020) Stringency in policy responses to Covid-19 pandemic and social distancing behavior in selected countries. SSRN Electron J. https://doi.org/10.2139/ssrn.3586319

Johns Hopkins University (2020) COVID-19 Case Tracker. Retrieved from https://coronavirus.jhu.edu/

Larson LR, Keith SJ, Fernandez M, Hallo JC, Shafer CS, Jennings V (2016) Ecosystem services and urban greenways: What's the public's perspective? Ecosyst Serv 22:111-116

Laster Pirtle WN (2020) Racial capitalism: a fundamental cause of novel coronavirus (COVID-19) pandemic inequities in the United States. Health Educ Behav. https://doi.org/10.1177/1090198120 922942

Lee JY, Lee DC (2014) Cardiac and pulmonary benefits of forest walking versus city walking in elderly women: a randomised, controlled, open-label trial. Eur J Integr Med 6(1):5-11

Li Q, Morimoto K, Nakadai A, Inagaki H, Katsumata M, Shimizu T, Kagawa T (2007) Forest bathing enhances human natural killer activity and expression of anti-cancer proteins. Int $\mathrm{J}$ Immunopathol Pharmacol 20(2_suppl):3-8

Monson E, Caron J, McCloskey K, Brunet A (2017) Longitudinal analysis of quality of life across the trauma spectrum. Psychol Trauma Theory Res Pract Policy 9(5):605

National Recreation and Parks Association (2020) Importance of Parks and Recreation. Retrieved from https://recreation.eku.edu/impor tance-parks-and-recreation

Nesbitt L, Meitner MJ, Girling C, Sheppard SR, Lu Y (2019) Who has access to urban vegetation? a spatial analysis of distributional green equity in 10 US cities. Landsc Urban Plan 181:51-79. https ://doi.org/10.1016/j.landurbplan.2018.08.007

Nicola M, Alsafi Z, Sohrabi C, Kerwan A, Al-Jabir A, Iosifidis C, Agha $\mathrm{R}$ (2020) The socio-economic implications of the coronavirus pandemic (COVID-19): a review. Int J Surg (London, England) 78:185. https://doi.org/10.1016/j.ijsu.2020.04.018

Public Health England (2014) Local action on health inequalities: improving access to green spaces. Public Health England, London. Retrieved from https://www.brillianto.biz/green-infrastruc ture/?q=node/1614

Randolph HE, Barreiro LB (2020) Herd Immunity: Understanding COVID- 19. Immunity 52(5):737-741
Rasmussen M, Laumann K (2013) The academic and psychological benefits of exercise in healthy children and adolescents. Eur J Psychol Educ 28(3):945-962. https://doi.org/10.1007/s1021 2-012-0148-z

Reynolds DL, Garay JR, Deamond SL, Moran MK, Gold W, Styra $R$ (2008) Understanding, compliance and psychological impact of the SARS quarantine experience. Epidemiol Infect 136(7):997-1007

Rice WL, Pan B (2020) Understanding drivers of change in park visitation during the COVID-19 pandemic: a spatial application of Big data. SocArXiv. https://doi.org/10.31235/osf.io/97qa4

Ritchie H, Ortiz-Ospina E, Beltekian D, Mathieu E, Hasell J, Macdonald B, Giattino C, Roser M (2020a). Policy Responses to the Coronavirus Pandemic. Retrieved from https://ourworldindata. org/policy-responses-covid

Ritchie H, Ortiz-Ospina E, Beltekian D, Mathieu E, Hasell J, Macdonald B, Giattino C, Roser M (2020b) Parks and outdoor spaces: How did the number of visitors change since the beginning of the pandemic? Retrieved from https://ourworldindata.org/graph er/change-visitors-parks-covid

Robertson E, Hershenfield K, Grace SL, Stewart DE (2004) The psychosocial effects of being quarantined following exposure to SARS: a qualitative study of Toronto health care workers. Can J Psychiatry 49(6):403-407

Roe J, Aspinall P (2011) The restorative benefits of walking in urban and rural settings in adults with good and poor mental health. Health Place 17(1):103-113

Rung AL, Mowen AJ, Broyles ST, Gustat J (2011) The role of park conditions and features on park visitation and physical activity. J Phys Activ Health 8(s2):S178-S187. https://doi.org/10.1123/ jpah.8.s2.s178

Pallant J (2010) SPSS survival manual-a step by step guide to data analysis using SPSS, 4th edn. Allen \& Unwin, Crows Nest

Sallis JF, Pratt M (2020) Multiple benefits of physical activity during the Coronavirus pandemic. Rev Bras Ativ Fís Saúde. https://doi. org $/ 10.12820 /$ rbafs. $25 \mathrm{e} 0112$

Samuelsson K, Barthel S, Colding J, Macassa G, Giusti M (2020) Urban nature as a source of resilience during social distancing amidst the coronavirus pandemic. Landsc Urban Plan. https://doi. org/10.31219/osf.io/3wx5a

Saunders MJ, Evans CA (2020) COVID-19, tuberculosis, and poverty: preventing a perfect storm. Eur Respir J 56:2001348. https://doi. org/10.1183/13993003.01348-2020

Seaman PJ, Jones R, Ellaway A (2010) It's not just about the park, it's about integration too: why people choose to use or not use urban greenspaces. Int J Behav Nutr Phys Act 7:78. https://doi. org/10.1186/1479-5868-7-78

Slater SJ, Christiana RW, Gustat J (2020) Peer Reviewed: Recommendations for keeping parks and green space accessible for mental and physical health during COVID-19 and other pandemics. Prev Chronic Dis. https://doi.org/10.5888/pcd17.200204

Stier A, Berman M, Bettencourt L (2020) COVID-19 attack rate increases with city size. Mansueto Institute for Urban Innovation Research Paper Forthcoming. Available at SSRN: https://ssrn. com/abstract $=3564464$

Tamosiunas A, Grazuleviciene R, Luksiene D, Dedele A, Reklaitiene R, Baceviciene M, Milinaviciene E (2014) Accessibility and use of urban green spaces, and cardiovascular health: findings from a Kaunas cohort study. Environ Health 13(1):20. https://doi. org/10.1186/1476-069X-13-20

Thomsen JM, Powell RB, Allen D (2013) Park health resources: Benefits, values, and implications. Park Sci 30(2):30-36

Tsao TM, Tsai MJ, Hwang JS, Cheng WF, Wu CF, Chou CC, Su TC (2018) Health effects of a forest environment on natural killer cells in humans: an observational pilot study. Oncotarget 9(23):16501. https://doi.org/10.18632/oncotarget.24741 
Twohig-Bennett C, Jones A (2018) The health benefits of the great outdoors: a systematic review and meta-analysis of greenspace exposure and health outcomes. Environ Res 166:628-637

Vivier E, Tomasello E, Baratin M, Walzer T, Ugolini S (2008) Functions of natural killer cells. Nat Immunol 9(5):503-510

Wilken JA, Pordell P, Goode B, Jarteh R, Miller Z, Saygar BG, Yeiah A (2017) Knowledge, attitudes, and practices among members of households actively monitored or quarantined to prevent transmission of Ebola Virus Disease-Margibi County, Liberia: FebruaryMarch 2015. Prehospital Disaster Med 32(6):673-678

Wolff M, Scheuer S, Haase D (2020) Looking beyond boundaries: revisiting the rural-urban interface of Green Space Accessibility in Europe. Ecol Ind 113:106245. https://doi.org/10.1016/j.ecoli nd.2020.106245

World Health Organization (WHO) (2020) WHO Director-General's opening remarks at the media briefing on COVID-19 - 11 March
2020. Retrieved from https://www.who.int/dg/speeches/detail/ who-director-general-s-opening-remarks-at-the-media-briefingon-covid-19---11-march-2020

Wu KK, Chan SK, Ma TM (2005) Posttraumatic stress, anxiety, and depression in survivors of severe acute respiratory syndrome (SARS). J Trauma Stress Off Publ Int Soc Trauma Stress Stud 18(1):39-42

Xiang YT, Yang Y, Li W, Zhang L, Zhang Q, Cheung T, Ng CH (2020) Timely mental health care for the 2019 novel coronavirus outbreak is urgently needed. Lancet Psychiatry 7(3):228-229

Publisher's Note Springer Nature remains neutral with regard to jurisdictional claims in published maps and institutional affiliations. 